\title{
Encapsulation of Adipose Stromal Vascular Fraction Cells in Alginate Hydrogel Spheroids Using a Direct-Write Three-Dimensional Printing System
}

\author{
Stuart K. Williams, Jeremy S. Touroo, Kenneth H. Church, ${ }^{1}$ and James B. Hoying ${ }^{1}$
}

\begin{abstract}
The study of tissue function in vitro has been aided by the development of three-dimensional culture systems that more accurately duplicate the complex cell components of tissues and organs. Bioprinting of cells provides a rapid tissue fabrication technique that can be used to evaluate normal and pathologic conditions in vitro as well as to construct complex three-dimensional tissue structures for implantation in regenerative medicine therapies. Studies were performed using a direct write three-dimensional bioprinting system to fabricate adipose-derived stromal vascular fraction cell spheroids. Human fat-derived stromal vascular fraction cells were mixed in $1.5 \%(\mathrm{w} / \mathrm{v})$ alginate solutions, and fabrication conditions were varied to produce an array of spheroids. The spheroids were placed in spinner culture, and spheroid integrity and encapsulated cell viability were assessed for 16 days. Results establish the ability to tightly control adipose SVF spheroids in the range of $800-1500 \mu \mathrm{m}$. Fabrication conditions were used to control spheroid size, and the results illustrate the ability to construct spheroids of precise size and shape. The adipose SVF cell population remains viable and the spheroid integrity was maintained for 16 days in suspension culture. The direct-write printing of adipose stromal vascular fraction cell containing spheroids provides a rapid fabrication technology to support in vitro microphysiologic system studies.
\end{abstract}

Key words: cell culture; stem cells; tissue engineering

\section{Introduction}

T HE USE OF THREE-DIMENSIONAL (3D) ENVIRONMENTS for cell culture provides a more physiological relevant system for in vitro modeling of cell behavior. Tissues are composed of multiple cell types, and cells are organized in specific spatial arrangements providing orientation of cells into geometries specific to organ functions. The study of cell function in vitro, originally utilizing cells grown on tissue culture surfaces (e.g., glass and plastic), has now transitioned to 3D cultures of cells often embedded in collagen gels. Coordinately, investigators have evaluated the ability of twodimensional and 3D cell cultures to undergo the formation of spheroids. Epithelial, neuronal, and endothelial organoid cultures have been established in this way. ${ }^{1-5}$ In this procedure embryonic stem cells are cultured as hanging drops and allowed to form embryoid bodies. ${ }^{6,7}$ Spheroid culture strategies have progressed to include endothelium, representing cells of the vasculature, a common cellular component of all complex tissues. ${ }^{8-10}$ And recently, complex 3D tissue con- structs containing parenchymal cells and vascular cells have been implanted in experimental models. ${ }^{11,12}$ These studies show that functional tissue organoids can be constructed in vitro and implanted in tissue, with evidence of vascular integration between implanted and recipient circulations and restoration of tissue function by the organoids.

The formation of 3D tissue constructs has now been evaluated using bioprinting technologies. ${ }^{13-16}$ Bioprinting, the biologic equivalent of computer-assisted design (CAD) and subsequent computer-assisted manufacturing (CAM) technologies includes several different fabrication systems including direct-write bioprinting and ink-jet bioprinting. ${ }^{13,17,18}$ These systems provide CAD-CAM-based methods for the controlled deposition of biological materials toward the fabrication of complex biological structures.

The present study has evaluated the use of a direct-write bioprinting instrument to form cellular spheroids constructed by using adipose-derived stromal vascular fraction (SVF) cells. The adipose SVF cell population represents a complex mixture of regenerative cells capable of forming tube-like 
cellular structures in 3D culture. Interestingly, this cell population also contains a population of cells that can differentiate into smooth and cardiac muscle cells, adipocytes, and chondrocyte precursors. ${ }^{14,19-21}$ Thus, the adipose SVF cell population represents a multipotent mixed cell population amenable for the study of complex cell and tissue functions. As described here, bioprinting conditions have been established that support the construction of adipose SVF-derived spheroids of precisely controlled dimensions. The spheroids maintain their shape when cultured in suspension using a spinner culture flask. Bioprinting of adipose SVF cell-containing spheroids provides a means toward rapid fabrication of complex spheroid constructs for use in 3D in vitro studies and a controlled dose cell delivery system for regenerative medicine therapies.

\section{Methods}

\section{Adipose-derived SVF cells}

Adipose SVF was derived from human fat obtained under Institutional Review Board exemption, through nonultrasonic suction-assisted liposuction of abdominal regions. The adipose SVF cell population was obtained according to established methods. ${ }^{22-24}$ Briefly, adipose tissue was rinsed with $0.1 \%$ bovine serum album (BSA) in phosphate-buffered saline (PBS), finely minced, and vigorously shaken in $2 \mathrm{mg} / \mathrm{mL}$ type I collagenase (Worthington Biochemical Company, Freehold, $\mathrm{NJ}$ ) for $40 \mathrm{~min}$ at $37^{\circ} \mathrm{C}$ for optimal digestion. The SVF cells were pelleted via centrifugation, and buoyant adipocytes discarded. The pellet was then washed once more with $0.1 \%$ BSA-PBS and plated onto gelatin-coated tissue culture flasks. Adherent cells were expanded to confluence and frozen. For bioprinting, cells were thawed, plated onto gelatin-coated tissue culture flasks, and grown to confluence in a $5 \% \mathrm{CO}_{2}$, $37^{\circ} \mathrm{C}$ incubator. Culture medium consisted of Medium 199, $20 \%$ fetal bovine serum (FBS), $5 \mathrm{mM}$ HEPES buffer, $2 \mathrm{mM}$ L-glutamine, and endothelial growth supplement containing heparin. The cells were released from the culture surfaces, suspended in $1.5 \%(\mathrm{w} / \mathrm{v})$ alginate at a concentration of $3 \times 10^{6}$ cells $/ \mathrm{mL}$, and used immediately.

\section{Bioprinter}

The major elements of this device are the computer-assisted design element, the delivery system including precision controlled pen movement, the precision liquid delivery system, and the environmental chamber that maintains a sterile environment during spheroid preparation. The design and control of the bioprinter have been previously reported. $^{15,25-28}$

\section{Suspension cell culture}

Following bioprinting and gelation in $\mathrm{CaCl}_{2}$, alginate spheroids encapsulating SVF cells were transferred to a spinner flask containing serum-supplemented culture medium using a $25-\mathrm{mL}$ serological pipet. Culture medium was composed of Medium 199, 20\% FBS, $5 \mathrm{mM}$ HEPES buffer, $2 \mathrm{mM}$ L-glutamine, endothelial growth supplement containing heparin, amphotericin B $(295 \mathrm{ng} / \mathrm{mL})$, penicillin $(45 \mathrm{U} / \mathrm{mL})$, and streptomycin $(45 \mu \mathrm{g} / \mathrm{mL})$. The spinner flask $(125-\mathrm{mL}$ MagnaFlex Microcarrier Spinner Flask, Wheaton Industries, Millville, NJ) was used with a magnetic stirrer platform (MCS 104-L Biological Stirrer, Techne Inc., Burlington, NJ) to provide convective mixing of the culture medium. Rotational speed of the magnetic impeller was set to $5 \mathrm{rpm}$ for 2 days and then increased to $10 \mathrm{rpm}$ for the remaining time frame. Dynamic culture was carried out in a $5 \% \mathrm{CO}_{2}, 37^{\circ} \mathrm{C}$ incubator for a total of 16 days. Spheroids were removed from the spinner flask for analysis at specific time points using a 25-mL serological pipet.

\section{Viability assessment}

Viability of encapsulated cells was assessed using a live/ dead staining system (Live/Dead Viability/Toxicity Kit, Life Technologies Inc., Carlsbad, CA). Spheroids were washed in Dulbecco's PBS (D-PBS), incubated in $10 \mu \mathrm{M}$ calcein AM (live stain) and in $10 \mu \mathrm{M}$ ethidium homodimer-1 (dead stain), and visualized by epifluorescent microscopy. Qualitative evaluation of fluorescent micrographs was performed to obtain an estimate of cell viability.

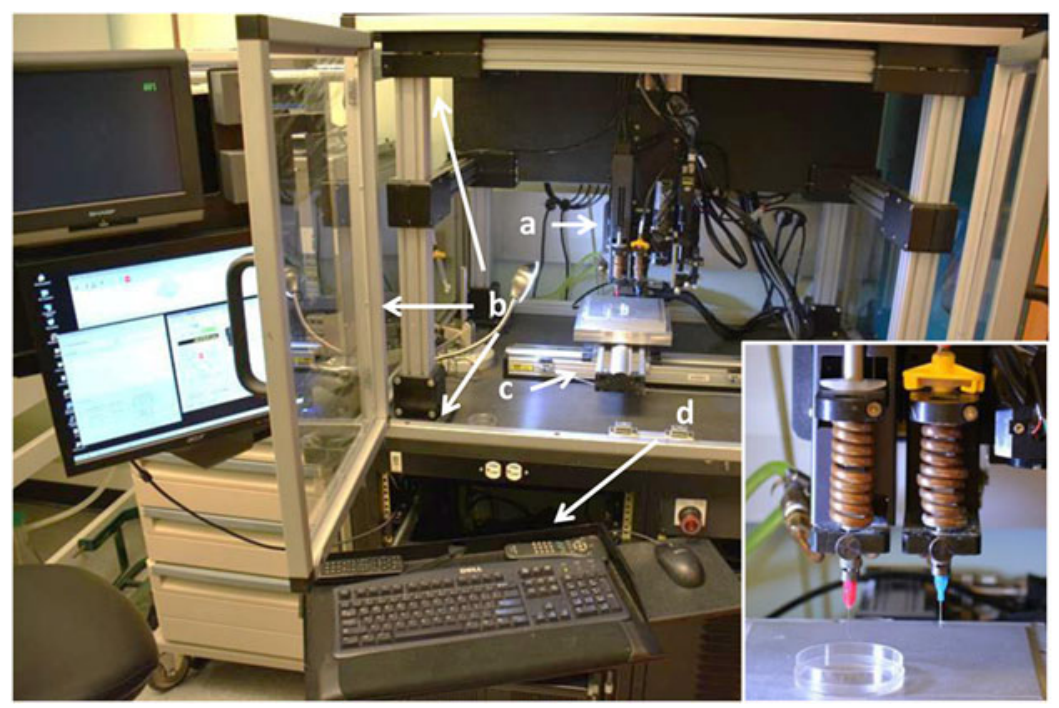

FIG. 1. The BioAssembly Tool bioprinter used for the creation of adipose stromal vascular fraction (SVF) cell spheroids. The bioprinter is composed of a pen delivery gantry with Z-axis control (a) housed in an environmental chamber (b). Inset: A higher magnification of the bioprinter pen system. A stage with $X$ and $Y$ axis control is mounted below the pens (c). The bioprinter is controlled by an integrated computer system (d). 
FIG. 2. Process for bioprinting spheroids. The human SVF cell population is mixed in $1.5 \%$ alginate, and this cell suspension is placed in a delivery pen. Extrusion of fluid is controlled by increasing the pressure in the delivery pen to a specific value, causing a droplet to form. The delivery pen is then lowered toward the $\mathrm{CaCl}_{2}$ solution at a rate of $5 \mathrm{~mm} / \mathrm{sec}$. The suspended droplet subsequently overcomes the surface tension, and a spheroid forms within the $\mathrm{CaCl}_{2}$ solution.

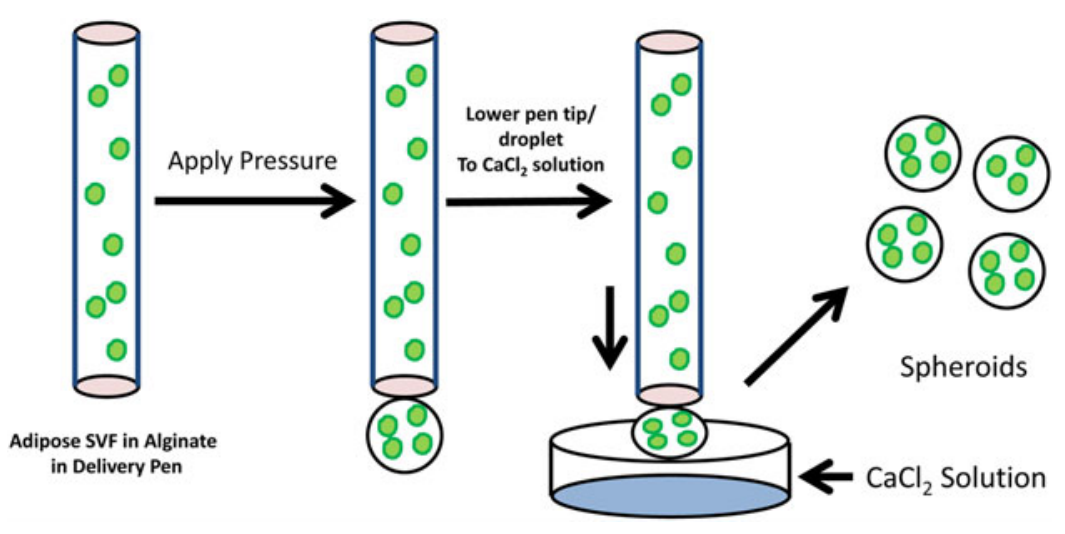

\section{Histology}

In preparation for hematoxylin and eosin (H\&E) staining, spheroids cultured in a spinner flask for 9 days were fixed in $1 \times$ HistoChoice (Amresco, Solon, $\mathrm{OH}$ ) diluted in D-PBS. The fixed spheroids were embedded in a gel block (HistoGel, Thermo Scientific, Waltham, MA) to secure the spheroids for processing and sectioning. The resulting gel construct was treated with $10 \%$ neutral-buffered formalin, infiltrated with paraffin, and embedded in paraffin. This second fixation step was used to cross-link the HistoGel and immobilize the spheroids in the gel. A microtome was used to obtain $6-\mu$ m sections, which were then stained with H\&E and viewed by brightfield microscopy.

\section{Scanning electron microscopy}

Spheroids, fixed in HistoChoice/D-PBS, were prepared for scanning electron microscopy (SEM) through dehydration in a series of graded ethanol and drying using hexamethyldisilazane (HMDS). Dehydrated spheroids were exposed to two consecutive 30-min immersions in HMDS, after which the HMDS was allowed to evaporate, resulting in dried specimens. The dried spheroids were sputter coated with gold and visualized by SEM (JSM-820 Scanning Electron Microscope, Jeol, Tokyo, Japan).

\section{Results}

The direct-write bioprinter used in the fabrication of the adipose SVF spheroids is illustrated in Figure 1. This instrument is referred to as the BioAssembly Tool and is composed of a computer for creation of specific scripts to drive the delivery pens and control delivery pen conditions, a movable stage, and an environmental chamber. The inset photograph in Figure 1 (bottom right) illustrates two delivery pens mounted on a motorized assembly that provides precision movement of the pens in the $Z$ axis. All pen and stage movements are controlled by the integrated computer system, which provides synchronized motion and dispensing for controlled delivery of cell-gel solutions.

The basic strategy for fabrication of the adipose SVF spheroids is illustrated in Figure 2. Human adipose-derived SFV
FIG. 3. Photographs illustrating the movement of the pen tip and alginate droplet toward the $\mathrm{CaCl}_{2}$ solution. The time sequence shown represents sequential frames illustrating the compression of the alginate droplet against the surface of the $\mathrm{CaCl}_{2}$ solution as the pen drops at a rate of $5 \mathrm{~mm} / \mathrm{sec}$. In the last frame the droplet has detached from the pen tip forming a spheroid. The spheroid in the $\mathrm{CaCl}_{2}$ solution is identified with arrowheads.
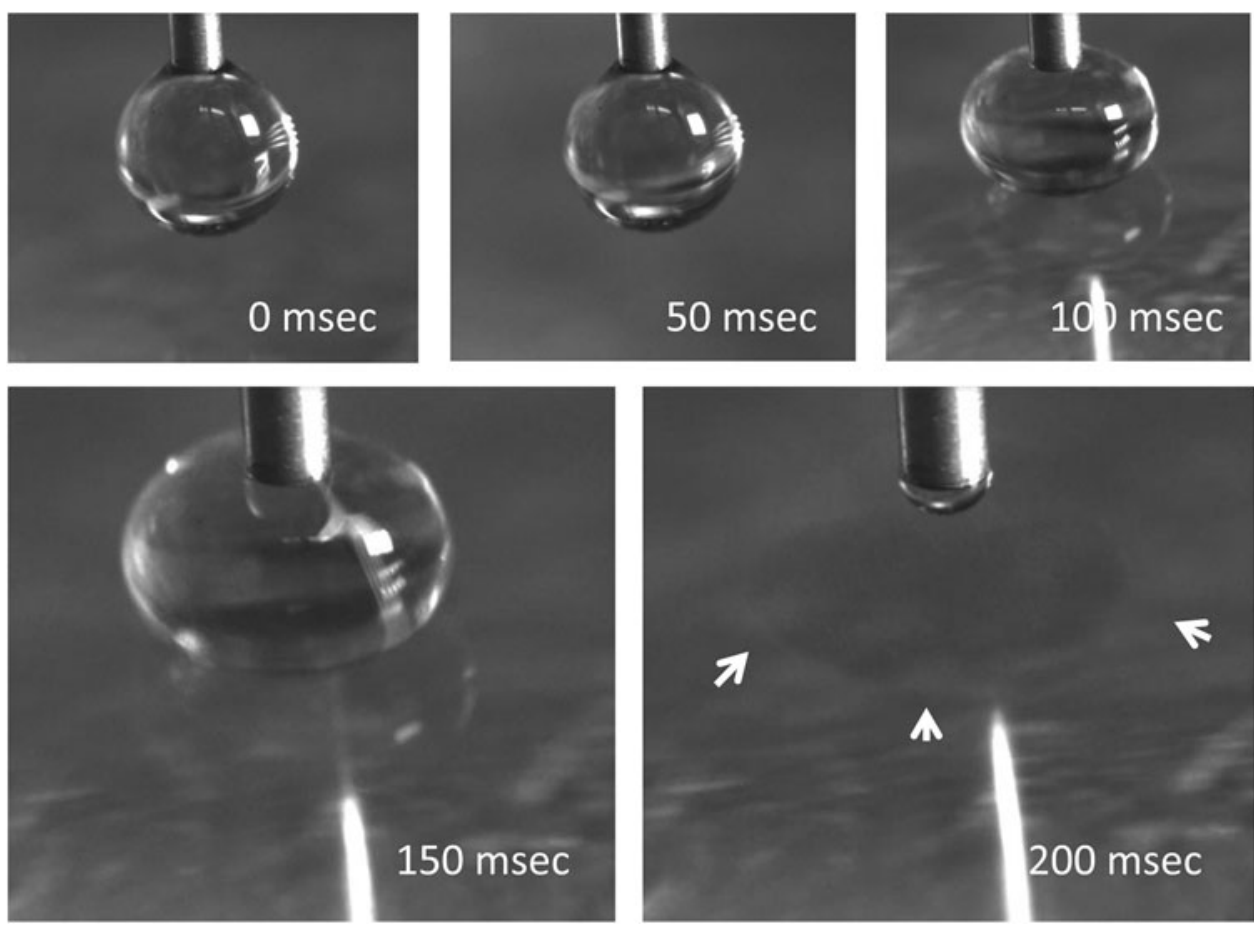


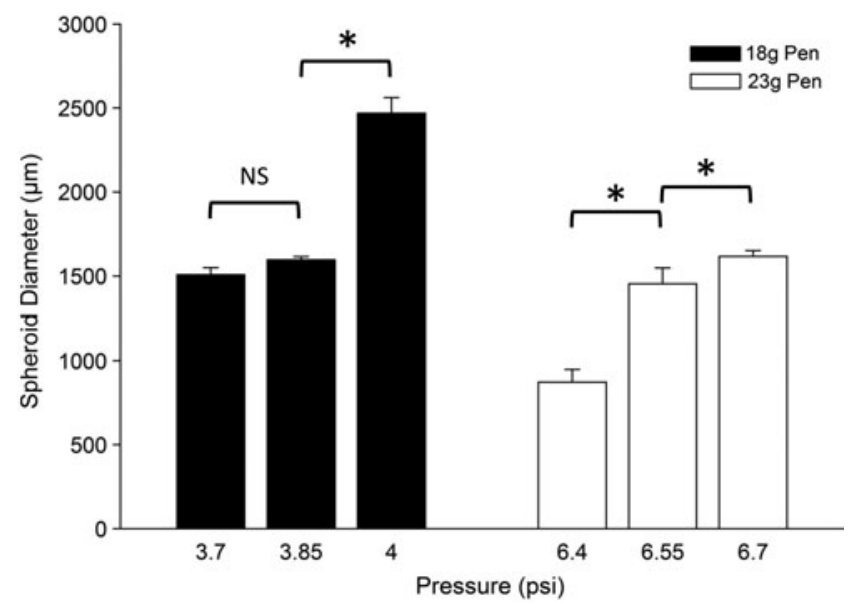

FIG. 4. The size of the spheroids formed is dependent upon both the size of the pen (18-gauge [18g] and 23 gauge [23g]) and the pressure used to extrude the alginate solution through the pen tip. The data are plotted as the mean $\pm S D$; NS, not significant. *Significant difference $(p<0.05)$ between test groups based on ANOVA statistical analysis between groups.

cells are suspended in $1.5 \%$ alginate, and the cell-alginate suspension is placed in a 3-mL delivery pen. Under computer control the delivery pen tip is advanced above a solution of $75 \mathrm{mM} \mathrm{CaCl}_{2}$, and a cell-alginate droplet forms at the tip using air pressure. The pen tip is subsequently lowered into the $\mathrm{CaCl}_{2}$ solution. The cycle time for droplet formation, pen lowering, spheroid formation, and pen repositioning is approximately $8 \mathrm{sec}$. This cycle time can be reduced to less than $1 \mathrm{sec}$ by reducing the dwell time at different steps.

A sequence of droplet formation to spheroid formation is illustrated in photomicrographs in Figure 3. The initial droplet formation results in a hanging drop that remains affixed to the pen tip (18 gauge). The pen is then lowered toward the surface of the $\mathrm{CaCl}_{2}$ solution. As seen in Figure 3C,D, as the pen advances along the $\mathrm{Z}$ axis (toward the $\mathrm{CaCl}_{2}$ solution), the droplet compresses and flattens against the surface. As illustrated in Figure 3E, the surface tension between the droplet and $\mathrm{CaCl}_{2}$ solution is then overcome, resulting in a spheroid in the $\mathrm{CaCl}_{2}$ solution.

The ability to control the size of the formed spheroids is illustrated in Figure 4. Two pens were used in this study (18 and 23 gauge), and the pressure head during droplet formation varied. For the 18-gauge pen, the pressure varied between 3.7 and 4 psi, resulting in a spheroid size distribution between 1500 and $2500 \mu \mathrm{m}$. For the 23-gauge pen, the pressure varied between 6.4 and 6.7 psi, resulting in a spheroid size distribution between 800 and $1700 \mu \mathrm{m}$. The size distribution at each pen tip dimension and pen delivery pressure was uniform.

The adipose SVF alginate spheroids were placed in spinner suspension culture and maintained at $37^{\circ} \mathrm{C}$ in a $5 \% \mathrm{CO}_{2}$ environment. During a 16-day incubation period, the individual spheroids remained separate with no evidence of spheroid clumping. Immediately after printing (day 0 ) and also following 1, 2, 3, 9, and 16 days in suspension culture, spheroids samples were evaluated by phase contrast microscopy for spheroid integrity, encapsulated cell morphology, and cell distribution. As illustrated in Figure 5 the spheroid size and cell distribution was maintained during the 16 days of spinner culture. Figure 6 illustrates the distribution of cells within the spheroids after 9 days of spinner culture using phase contrast (Fig. 6A) and epifluorescence (Fig. 6B, bisbenzimide nuclear staining), and the viability of cells by evaluating live cells (Fig. 6C) and dead cells (Fig. 6D). The cell viability evaluated using this live/dead cytochemical analysis was estimated to be $>90 \%$.

Figure 7 illustrates the surface morphology of an adipose SVF spheroid fixed immediately following printing and evaluated by SEM. The spheroids were dried using a dehydrating solution (HMDS) that resulted in significant artifactual shrinkage of the spheres. The uniformity of the spheroid was apparent.

In order to evaluate cellular morphology within the spheroids, samples were processed for paraffin sectioning and sections stained with H\&E. Representative sections (Fig. 8) illustrate the cell morphology of encapsulated cells immediately following printing (Fig. 8A) and after 9 days in spinner culture (Fig. 8B). Since the adipose SVF cell population is composed of a significant number of endothelium and other vascular cells, ${ }^{29}$ the presence of tube-like structures seen in cross section in this figure was not unexpected.
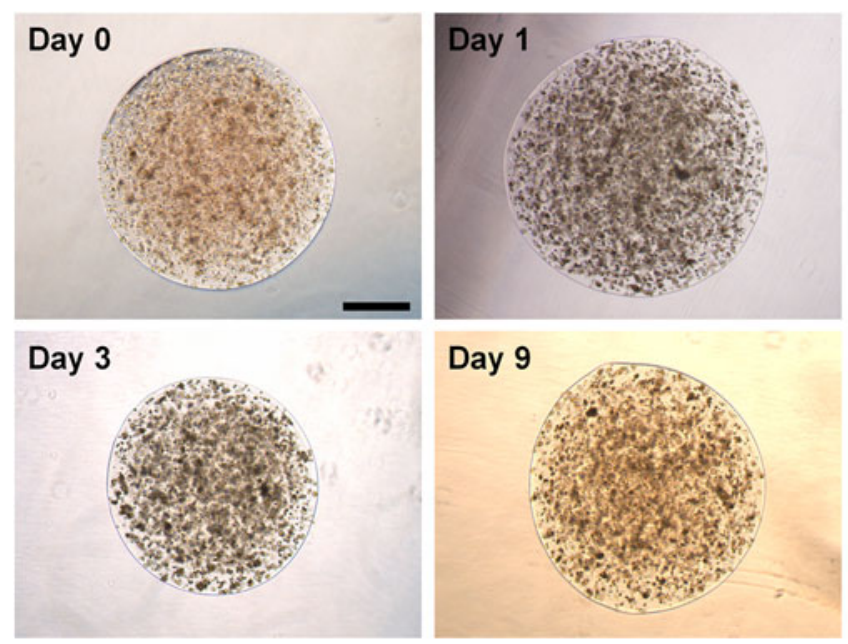
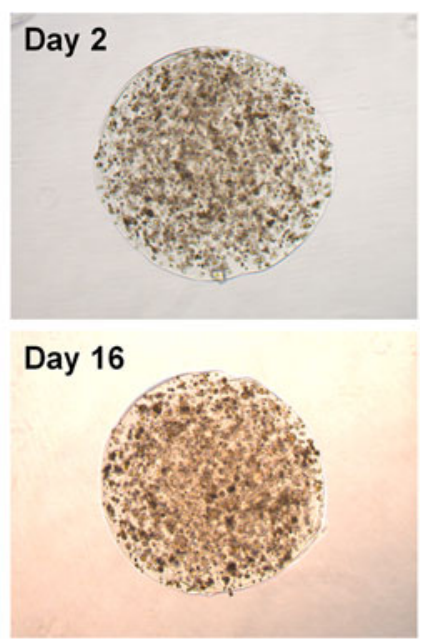

FIG. 5. Phase contrast micrographs of adipose SVF spheroids immediately after formation (day 0 ) and following culture in a spinner flask. Individual culture time points are identified. Bar $=500 \mu \mathrm{m}$. 

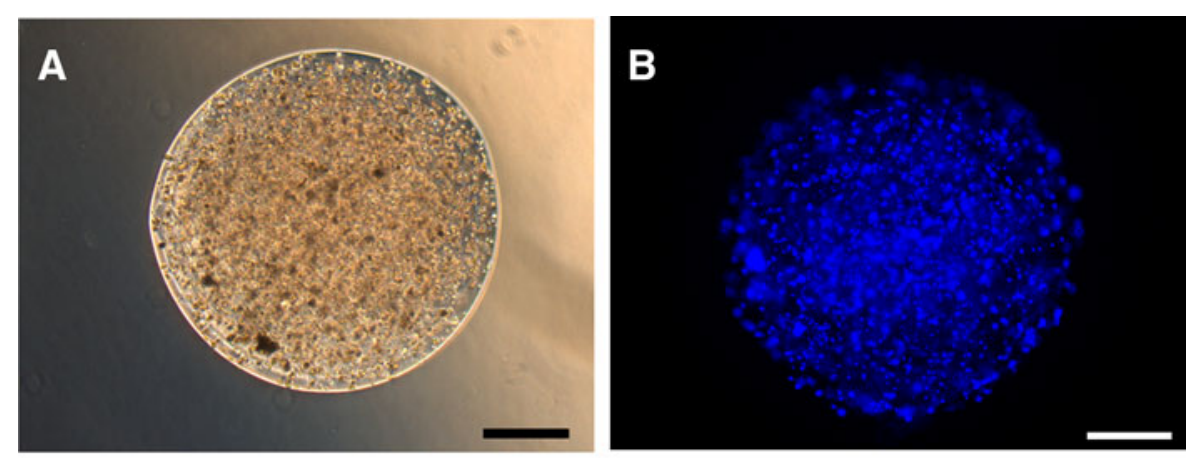

FIG. 6. Comparison of spheroid morphology by phase contrast microscopy (A), cell density and distribution using the nuclear stain bisbenzimide and visualized by epifluorescence (B) and evaluation of live (C) and dead (D) cells. Spheroids were cultured for 9 days in spinner culture. Bar $=500 \mu \mathrm{m}$.
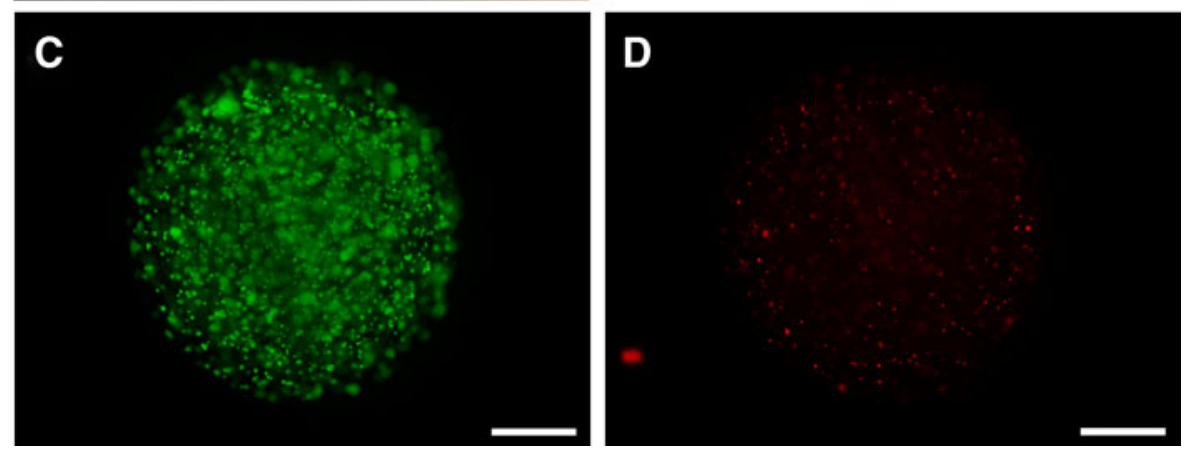

\section{Discussion}

Almost all of the cells in the body function in a 3D environment. As progress is made toward recapitulation of physiological systems in tissue culture environments, the importance of establishing cells in a 3D system has become apparent. ${ }^{30-32}$ The growth of mammalian cells in 3D culture systems has included many variations, including incorporation of cells in gels composed of extracellular matrix (e.g., collagen), fibrin gels, hydrogels including alginates, and the self-assembly of cells into spheroids (e.g., embryoid bodies). The current study was undertaken to evaluate the use of 3D bioprinting technology to create alginate spheroids that contained adipose-derived SVF cells. These adipose SVF containing spheroids were evaluated in suspension culture to establish the viability of encapsulated cells in prolonged culture.

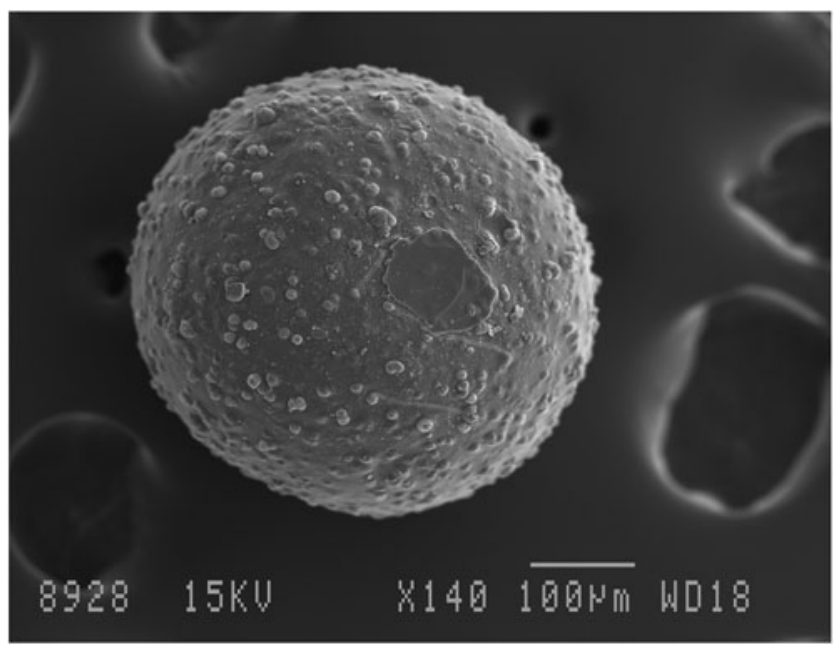

FIG. 7. Scanning electron micrograph of adipose SVF spheroid cultured for 9 days in spinner culture. Bar $=100 \mu \mathrm{m}$.
Direct-write bioprinting of cells in biocompatible gel systems has previously been used to construct 3D tissue mimics. Direct-write, pen-based delivery bioprinters are functionally different than ink-jet-based bioprinters in that the material printed can be significantly thicker or more viscous, which provides opportunity for more complex structures based on the delivery pen's size and the pressure characteristics of the solution extrusion. In the current study, a 3D bioprinter, with precise pen delivery characteristics and novel nano-dispensing pumps, was used to form adipose SVF spheroids with defined dimensions.

The formation of cell-containing spheroids by placing drops of cell-containing solutions of alginate onto $\mathrm{CaCl}_{2}$ has previously been reported by Akeda and colleagues. ${ }^{33}$ These authors manually expressed tumor cells suspended in alginate solutions through a 21-gauge needle and beads were formed as the alginate cell suspension penetrated a $\mathrm{CaCl}_{2}$ solution. Although not directly evaluated by Akeda and colleagues, the formation of the alginate beads by dropping solutions onto $\mathrm{CaCl}_{2}$ appears to result in spheroids of varying size and shape. The current method, using a bioprinter to form spheroids results in the formation of nearly perfect spheres, with minimal variability in size between spheroids. Advantages of bioprinting spheroids are the ability to precisely control the volume of each alginate droplet, control the rate of alginate penetration in the $\mathrm{CaCl}_{2}$ gelling solution, and accelerate the process of cycling between sequences of drop formation and $\mathrm{CaCl}_{2}$ penetration. The bioprinted spheroids are of uniform dimensions. As illustrated in the printing pen pressure versus spheroid size relationship, very small changes in the pressure head that drives alginate through the delivery pens will result in significant changes in sphere shape. The precise control of pressure-driven drop formation results in spheroids of uniform size. These results provide evidence that bioprinting can control the quantity of cells in each spheroid and thus, control cell delivery dose wherein spheroids could be delivered directly to tissues. 

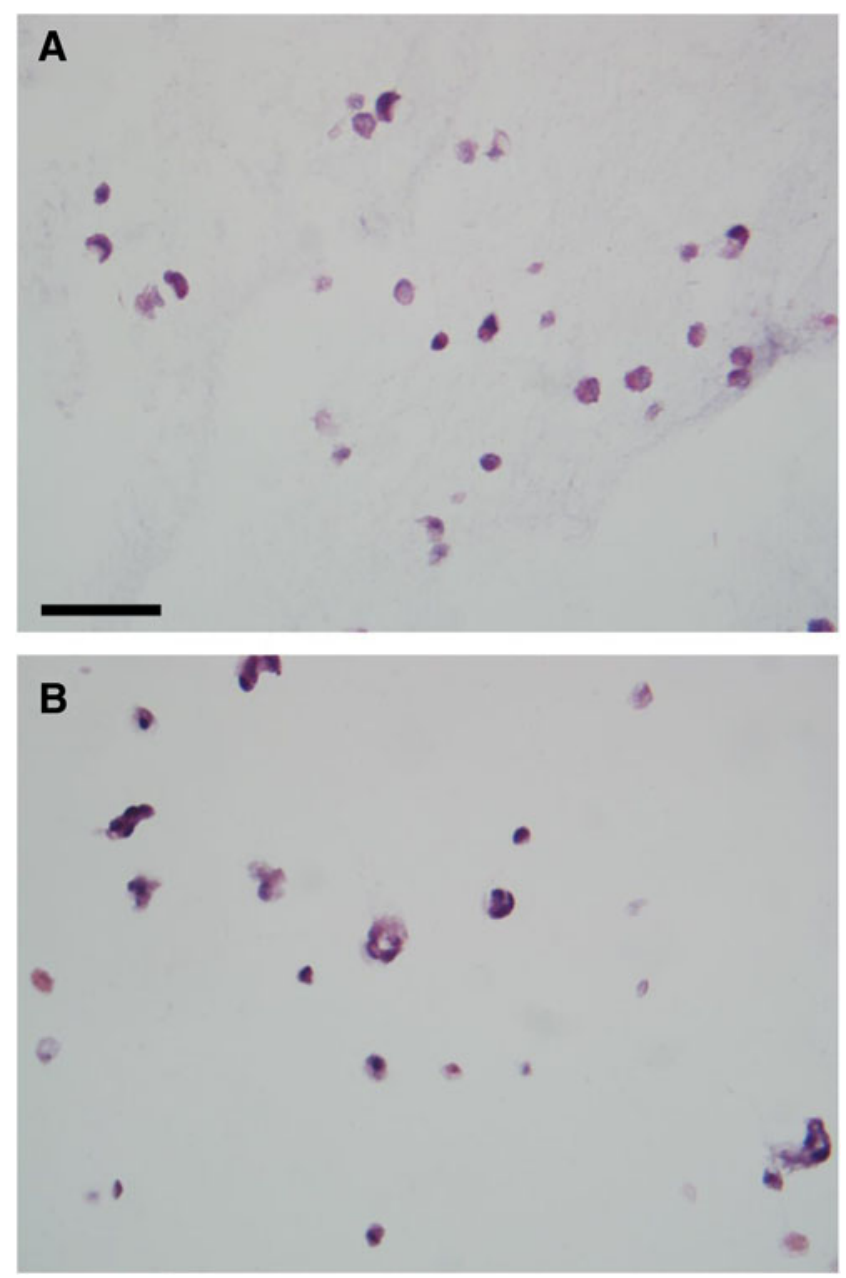

FIG. 8. Light micrographs of hematoxylin and eosin stained sections of adipose SVF containing spheroids immediately after formation (A) and following 9 days in culture (B). Bar $=50 \mu \mathrm{m}$.

The ability to culture spheroids for extended periods of time, up to 16 days in this report, has been achieved. The spheroids can be cultured in standard cell culture dishes (data not shown) as well as in suspension cultures. The maintenance of viable cells in these suspension cultures suggests this system would be amenable to other suspension culture systems including roller bottles and microgravity simulating rotation bioreactors. ${ }^{34}$ In the current study the adipose SVF cell population remains homogenously dispersed within the encapsulating gel. Also of interest, the diffusion of nutrients and waste products appears to be adequate because the viable cells are observed throughout the spheroid, with no evidence of a central core of dead cells.

Bioprinting of cell-containing spheroids provides a novel process to create 3D cultures of mammalian cells. The spheroids are amenable to many forms of suspension culture, and the use of these spheroids as a means to precisely control cell dose and cell potency offers intriguing opportunities for regenerative medicine.

\section{Acknowledgment}

The research presented in this manuscript was supported by the Gheens Foundation.

\section{Author Disclosure Statement}

No competing financial interests exist.

\section{References}

1. Todd GK, Boosalis CA, Burzycki AA, et al. Towards neuronal organoids: a method for long-term culturing of highdensity hippocampal neurons. PLoS One. 2013;8:e58996.

2. Kuratnik A, Giardina C. Intestinal organoids as tissue surrogates for toxicological and pharmacological studies. Biochem Pharmacol. 2013;85:1721-1726.

3. Ewald AJ. Isolation of mouse mammary organoids for longterm time-lapse imaging. Cold Spring Harb Protoc. 2013; 2013:130-133.

4. Hynds RE, Giangreco A. Concise review: the relevance of human stem cell-derived organoid models for epithelial translational medicine. Stem Cells. 2013;31:417-422.

5. Knight KR, Uda Y, Findlay MW, et al. Vascularized tissueengineered chambers promote survival and function of transplanted islets and improve glycemic control. FASEB J. 2006;20:565-567.

6. Pineda ET, Nerem RM, Ahsan T. Differentiation patterns of embryonic stem cells in two- versus three-dimensional culture. Cells Tissues Organs. 2013;197:399-410.

7. Ng YS, Ramsauer M, Loureiro RM, et al. Identification of genes involved in VEGF-mediated vascular morphogenesis using embryonic stem cell-derived cystic embryoid bodies. Lab Invest. 2004;84:1209-1218.

8. Mason BN, Starchenko A, Williams RM, et al. Tuning threedimensional collagen matrix stiffness independently of collagen concentration modulates endothelial cell behavior. Acta Biomater. 2013;9:4635-4644.

9. Vodyanik MA, Yu J, Zhang $X$, et al. A mesoderm-derived precursor for mesenchymal stem and endothelial cells. Cell Stem Cell. 2010;7:718-729.

10. Korff T, Kimmina S, Martiny-Baron G, et al. Blood vessel maturation in a 3-dimensional spheroidal coculture model: direct contact with smooth muscle cells regulates endothelial cell quiescence and abrogates VEGF responsiveness. FASEB J. 2001;15:447-457.

11. Nunes SS, Maijub JG, Krishnan L, et al. Generation of a functional liver tissue mimic using adipose stromal vascular fraction cell-derived vasculatures. Sci Rep. 2013;3:2141.

12. Hiscox AM, Stone AL, Limesand S, et al. An islet-stabilizing implant constructed using a preformed vasculature. Tissue Eng Part A. 2008;14:433-440.

13. Tasoglu S, Demirci U. Bioprinting for stem cell research. Trends Biotechnol. 2013;31:10-19.

14. Chang CC, Krishnan L, Nunes SS, et al. Determinants of microvascular network topologies in implanted neovasculatures. Arterioscler Thromb Vasc Biol. 2012;32:5-14.

15. Chang CC, Boland ED, Williams SK, et al. Direct-write bioprinting three-dimensional biohybrid systems for future regenerative therapies. J Biomed Mater Res B Appl Biomater. 2011;98:160-170.

16. Lee $W$, Pinckney J, Lee V, et al. Three-dimensional bioprinting of rat embryonic neural cells. Neuroreport. 2009;20:798-803.

17. Derby B. Printing and prototyping of tissues and scaffolds. Science. 2012;338:921-926.

18. Marga F, Jakab K, Khatiwala C, et al. Toward engineering functional organ modules by additive manufacturing. Biofabrication. 2012;4:1-12.

19. Zuk PA, Zhu M, Ashjian P, et al. Human adipose tissue is a source of multipotent stem cells. Mol Biol Cell. 2002;13:4279_ 4295. 
20. Nunes SS, Rekapally H, Chang CC, et al. Vessel arterial-venous plasticity in adult neovascularization. PLoS One. 2011;6:1-10.

21. Nunes SS, Greer KA, Stiening CM, et al. Implanted microvessels progress through distinct neovascularization phenotypes. Microvasc Res. 2010;79:10-20.

22. Williams SK, Matthews MA, Wagner RC. Metabolic studies on the micropinocytic process in endothelial cells. Microvasc Res. 1979;18:175-184.

23. Wagner RC, Matthews MA. The isolation and culture of capillary endothelium from epididymal fat. Microvasc Res. 1975;10:286-297.

24. Wagner RC, Kreiner P, Barrnett RJ, et al. Biochemical characterization and cytochemical localization of a catecholaminesensitive adenylate cyclase in isolated capillary endothelium. Proc Natl Acad Sci USA. 1972;69:3175-3179.

25. Chang CC, Krishnan L, Reese S, et al. In vitro patterned microvessels lose alignment in vivo. 9th World Congress for Microcirculation. Paris, France. Sept. 25-28, 2010.

26. Smith CM, Christian JJ, Warren WL, et al. Characterizing environmental factors that impact the viability of tissueengineered constructs fabricated by a direct-write bioassembly tool. Tissue Eng. 2007;13:373-383.

27. Smith CM, Cole Smith J, Williams SK, et al. Automatic thresholding of three-dimensional microvascular structures from confocal microscopy images. J Microsc. 2007;225(Pt 3):244-257.

28. Smith CM, Stone AL, Parkhill RL, et al. Three-dimensional bioassembly tool for generating viable tissue-engineered constructs. Tissue Eng. 2004;10:1566-1576.

29. Williams SK, Wang TF, Castrillo R, et al. Liposuction-derived human fat used for vascular graft sodding contains endothelial cells and not mesothelial cells as the major cell type. J Vasc Surg. 1994;19:916-923.

30. Kellar RS, Williams SK, Naughton GK, et al. Threedimensional fibroblast cultures stimulate improved ventricular performance in chronically ischemic canine hearts. Tissue Eng Part A. 2011;17:2177-2186.
31. Pedersen JA, Lichter S, Swartz MA. Cells in 3D matrices under interstitial flow: effects of extracellular matrix alignment on cell shear stress and drag forces. J Biomech. 2010; 43:900-905.

32. Griffith LG, Swartz MA. Capturing complex 3D tissue physiology in vitro. Nat Rev Mol Cell Biol. 2006;7:211-224.

33. Akeda K, Nishimura A, Satonaka H, et al. Three-dimensional alginate spheroid culture system of murine osteosarcoma. Oncol Rep. 2009;22:997-1003.

34. Sanford GL, Ellerson D, Melhado-Gardner C, et al. Threedimensional growth of endothelial cells in the microgravity-based rotating wall vessel bioreactor. In Vitro Cell Dev Biol Anim. 2002;38:493-504.

Address correspondence to: Stuart K. Williams, PhD Cardiovascular Innovation Institute 302 E. Muhammad Ali Blvd. Louisville, KY 40202

E-mail: stu.williams@louisville.edu

\begin{aligned} & \multicolumn{1}{c|}{ Abbreviations Used } \\ & $3 \mathrm{D}=$ three-dimensional \\ & $\mathrm{BSA}=$ bovine serum albumin \\ & $\mathrm{CAD}=$ computer-assisted design \\ & $\mathrm{CAM}=$ computer-assisted manufacturing \\ & $\mathrm{D}-\mathrm{PBS}=$ Dulbecco's phosphate-buffered saline \\ & $\mathrm{FBS}=$ fetal bovine serum \\ & $\mathrm{H} \& \mathrm{E}=$ hematoxylin and eosin \\ & $\mathrm{HMS}=$ hexamethyldisilazane \\ & $\mathrm{PBS}=$ phosphate-buffered saline \\ & $\mathrm{SEM}=$ scanning electron microscopy \\ & $\mathrm{SVF}=$ stromal vascular fraction \end{aligned}

